\title{
APLIKASI PELAPORAN DATA OPERASIONAL SUMUR-SUMUR MINYAK DAN GAS DI PETROGAS ISLAND LIMITED SALAWATI BERBASIS WEB
}

\section{OPERATIONAL DATA REPORTING APPLICATION OF OIL AND GAS WELLS IN PETROGAS ISLAND LIMITED SALAWATI WEB-BASED}

\author{
Iriene Surya Rajagukguk ${ }^{1}$, Velly Bernard Latul ${ }^{2}$ \\ ${ }^{12}$ Program Studi Sistem Informasi, Universitas Victory Sorong, Indonesia \\ 1irenerajagukguk1985@gmail.com, ${ }^{2}$ velly@gmail.com
}

\begin{abstract}
Abstrak
Tujuan melakukan penelitian ini untuk membantu para karyawan khususnya di divisi production maintenance dibagian clerck dalam melakukan pelaporan pendataan Sumur - Sumur Minyak dan Gas, sehingga dapat juga membantu meminimalkan penggunaan kertas secara berlebihan. Sistem ini menggunakan perangkat lunak XAMPP, $P H P$, dan MySQL. Xampp digunakan sebagai perangkat lunak web server, $P H P$ digunakan sebagai bahasa pemograman script server-side yang didesain untuk pengembangan web, sedangkan $M y S Q L$ digunakan sebagai perangkat lunak pembuatan database. Hasil dari penelitian ini adalah Aplikasi Pendataan Pelaporan Sumur - Sumur Minyak dan Gas yang sangat membantu pekerjaan admin Clerk dalam mengelola data Sumur Minyak dan Gas, dan data yamg dikelola admin clerk lebih teratur dan juga dapat meminimalakan penggunaan kertas secara berlebihan.bagi pemimpin lebih muda dalam mendapatkan dan melihat informasi data - data sumur dan Gas.
\end{abstract}

Kata kunci: Pengelola data, pelaporan, xampp, php, mysql

\begin{abstract}
The purpose of conducting this research is to help employees, especially in the production maintenance division in clerck in reporting the logging of Wells - Oil and Gas Wells, so as to also help minimize the excessive use of paper. The system uses XAMPP, PHP, and MySQL software. Xampp is used as a web server software, PHP is used as a server-side script programming language designed for web development, while MySQL is used as database creation software. The result of this study is the Well Reporting Logging Application - Oil and Gas Wells which greatly assists the clerk admin's work in managing Oil and Gas Well data, and yamg data is managed by admin clerks more regularly and can also minimize excessive use paper. Younger leaders in obtaining and viewing data information - well and gas data.
\end{abstract}

Keywords: Data manager, reporting, xampp, php, mysql

\section{PENDAHULUAN}

Petrogas Island Limited Salawati, yang baru saat ini berdiri secara resmi pada tanggal 23 April, Tahun 2020 dan menggantikan perusahaan yang lama yaitu Job Pertamina Petrochina Salawati. Dalam 
Melaksanakan operasional perusahaan, kegiatan operasional perusahaan selalu terkontrol dan mempunyai laporan - laporan kerja setiap harinya, baik menyangkut operasional karyawan atau material, salah satunya adalah mengenai pendataan sumur - sumur Minyak dan Gas. Sistem informasi pelaporan pendataan sumur - sumur Minyak dan Gas berperan penting dalam administrasi sebagai sumber informasi dan pendokumentasikan.

Petrogas Island Limited Salawati, dalam pelaporan pendataan sumur - sumur Minyak dan Gas masih menggunakan Aplikasi Microsoft Excel. penggunaan aplikasi ini di nilai masih kurang memadai untuk pelaporan pendataan sumur - sumur Minyak dan Gas.

Menggunakan Aplikasi Microsoft Excel adalah rutinitas bagi karyawan di bagian Clerck untuk menginput data operasional data sumur Minyak dan Gas, setelah semua data di input, data tersebut akan di kirim ke alamat e-mail masing - masing Supervisor, setelah terkirim data tersebut harus di print untuk menjadi file pendokumentasiaan.. Hal ini tentunya akan lebih banyak menghabiskan waktu dan penggunaan kertas.

Oleh karena itu, berdasarkan latar belakang masalah diatas, maka penulis mengangkat judul “Aplikasi Pelaporan Data Operasional Sumur - Sumur Minyak Dan Gas di Petrogas Island Limited Salawati Berbasis Web".

\section{DASAR TEORI /MATERIAL DAN METODOLOGI/PERANCANGAN}

\subsection{Dasar Teori}

Menurut Rizki Adhi Pratama, Jansen Wiratama, DKK (2017) dengan judul penelitian "Pengembangan Sistem Informasi Pendukung Pelaporan Proses Lifting Minyak" (Studi Kasus: Pt. Emp Malacca Strait S.A. Tbk). Dalam penelitian ini, penulis menggunakan metode pengembangan sistem berorientasi objek dengan alat perancangan Unified Modelling Language (UML) dan model pengembangan sistem strategi Rapid Application Development (RAD). Bahasa pemrograman yang digunakan adalah Hypertext Preprocessor (PHP) dan My Structure Query Language (MySQL) sebagai basis datanya. Sistem informasi pendukung pelaporan proses lifting minyak ini dapat meningkatkan tingkat akurasi informasi yang dibutuhkan pengguna dalam proses pelaporan data lifting minyak.

Menurut penelitian Lapu tombilayuk dan Zaini, Dkk (2020) Dengan Judul penelitian "Prototipe Sistem Informasi Pengelolaan Data Statistik Terpadu Kota Bontang" Dalam perancangan prototipe ini, peneliti melakukan beberapa tahap yaitu pertama analisis sistem yang sedang berjalan melalui metode pengamatan langsung, wawancara dengan pengelolah data statistik, sehingga diperolah gambaran proses bisnis sistem yang sedang berjalan. Tahap kedua adalah metode penggambaran atau pemodelan sistem yang akan dibangun dengan menggunakan pemodelan logic (logical model) dengan membuat diagram konteks, perancangan basis data dan perancangan antar muka (interface) sistem. Dari penelitian ini menghasilkan rancangan prototipe sistem informasi yang digunakan oleh Tim perancangan sistem untuk membangun sistem informasi Pengelolaan Data Statistik Terpadu (SIMPATIKU) Kota Bontang.

Menurut Jefri Hutama Arb, Mangaras Yanu F, Dkk (2017), Dengan Judul penelitian "Pengembangan Aplikasi Data Warehouse Untuk Pengelolaan Sumur Minyak". Penelitian ini dilakukan untuk mengembangkan aplikasi yang mampu mangakomodir kebutuhan P.T. Geotama Energy dalam menjalankan usahanya untuk mgengelola data sumur minyak yang berupa Interface Data Warehouse. Aplikasi ini dikembangkan dengan metode prototyping dengan menggunakan bahasa pemrograman $P H P$ dan MySQL sebagai database. Hasil penelitian berupa aplikasi interface data warehouse untuk pengelolaan sumur minyak berbasis web. 


\subsection{METODE DAN PERANCANGAN SISTEM}

Lokasi penelitian ini dilakukan diperusahaan Petrogas Island Limited. Salawati yang beralamat di Distrik Salawati tengah, Salawati papua barat.

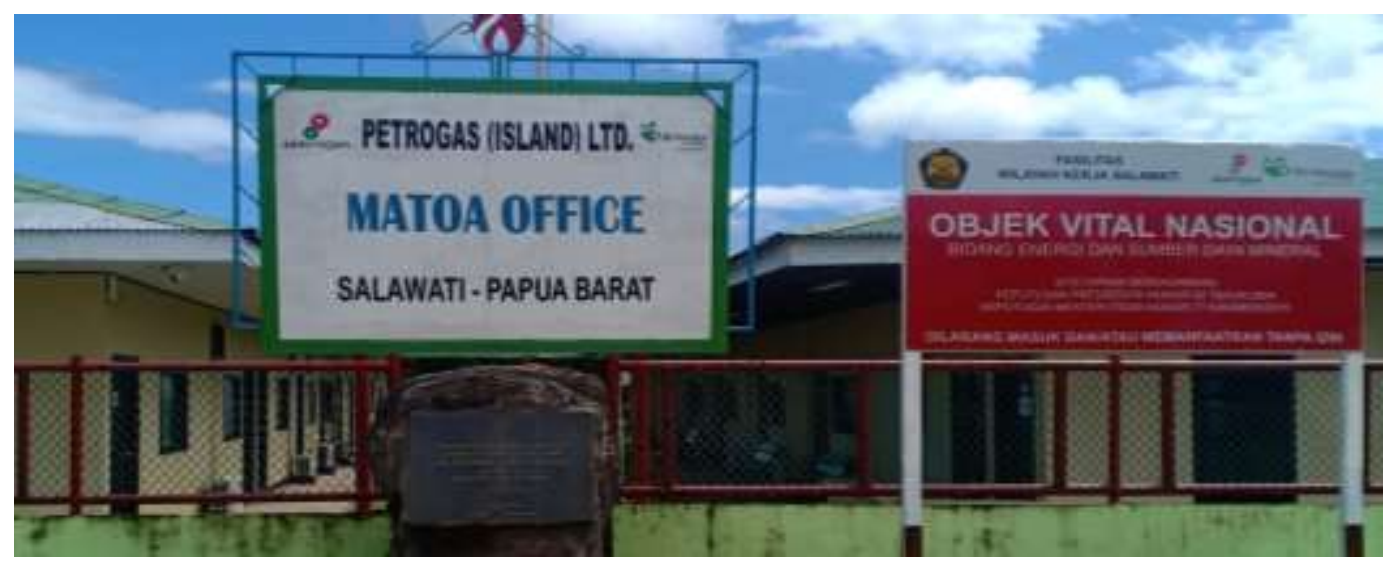

Gambar 1 Lokasi Penelitian

\section{Metode Penelitian}

Pengembangan sistem menggunakan waterfall. Model air terjun (waterfall), Mengambil kegiatan dasar seperti spesifikasi, pengembangan, validasi, dan evolusi dan merepresentasikannya sebagai fase seperti spesifikasi persyaratan, perancangan perangkat lunak, implementasi, pengujian dan seterusnya.

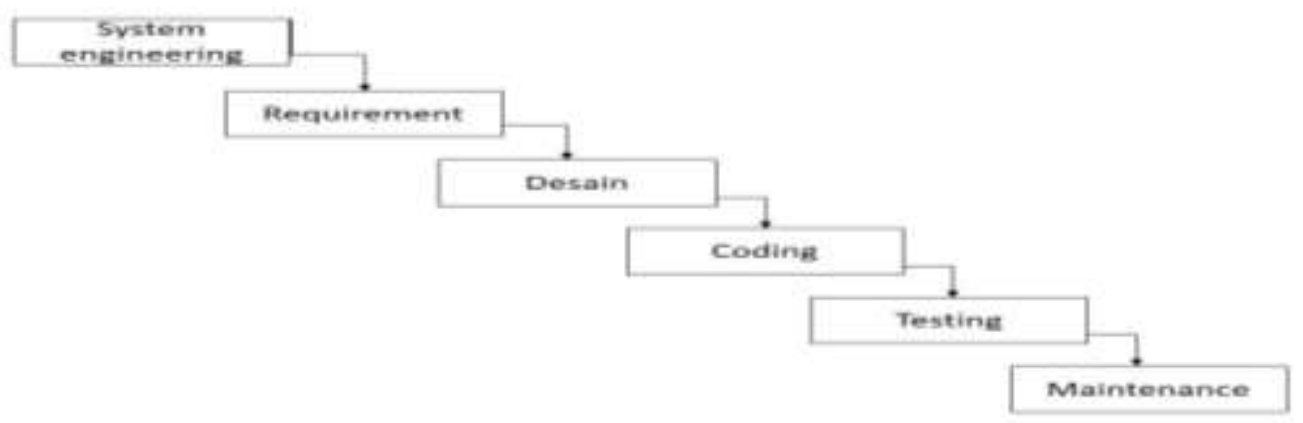

Gambar 2. Metode Waterfall

\section{Objek Penelitian}

Pada penelitian ini, yang menjadi objek penelitian adalah sistem pelaporan data Sumur Minyak dan Gas pada Petrogas Island Ltd Salawati, yang masih belum efektif. Dengan adanya sistem baru yang dibuat ini dapat membantu karyawan Production Maintenance khususnya di bagian clerck dalam melakukan pelaporan data agar dapat menimalisirkan kertas dan waktu.

\section{PEMBAHASAN}

\subsection{Implementasi Antar Muka}

Implementasi antar muka merupakan suatu gambar tampilan dari aplikasi yang telah dibuat, berikut merupakan implementasi antar muka perancangan aplikasi pelaporan data operasional Sumur - Sumur Minyak dan Gas 
a) Halaman Depan

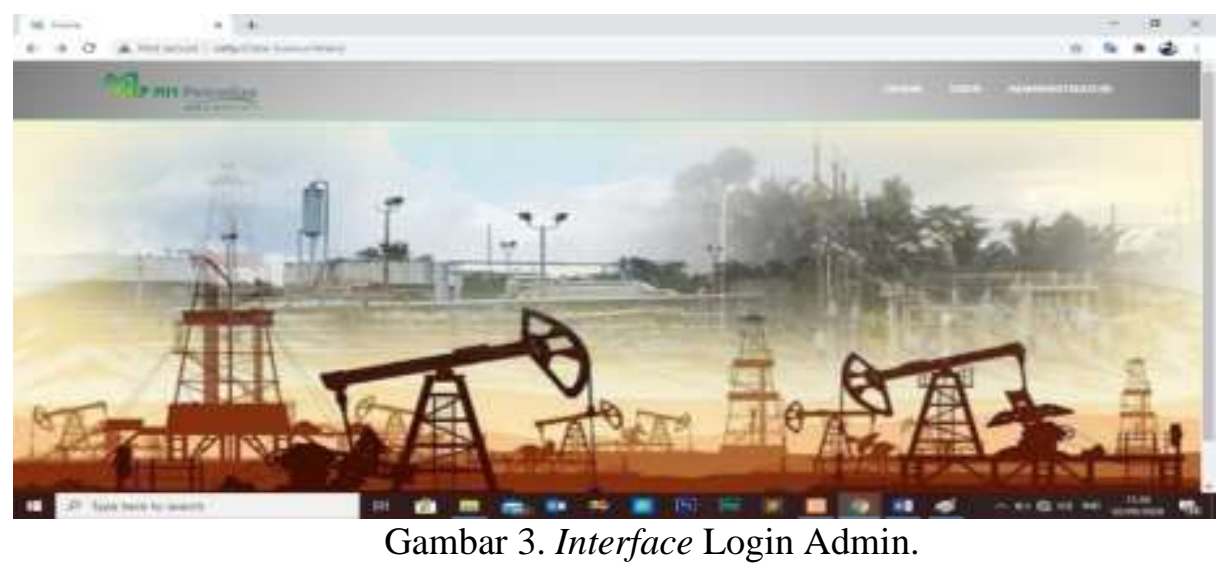

Gambar 3 di atas adalah halaman tampilan utama dari web menu untuk admin melakukan login sebelum masuk ke halaman admin.

b) Halaman Login Admin

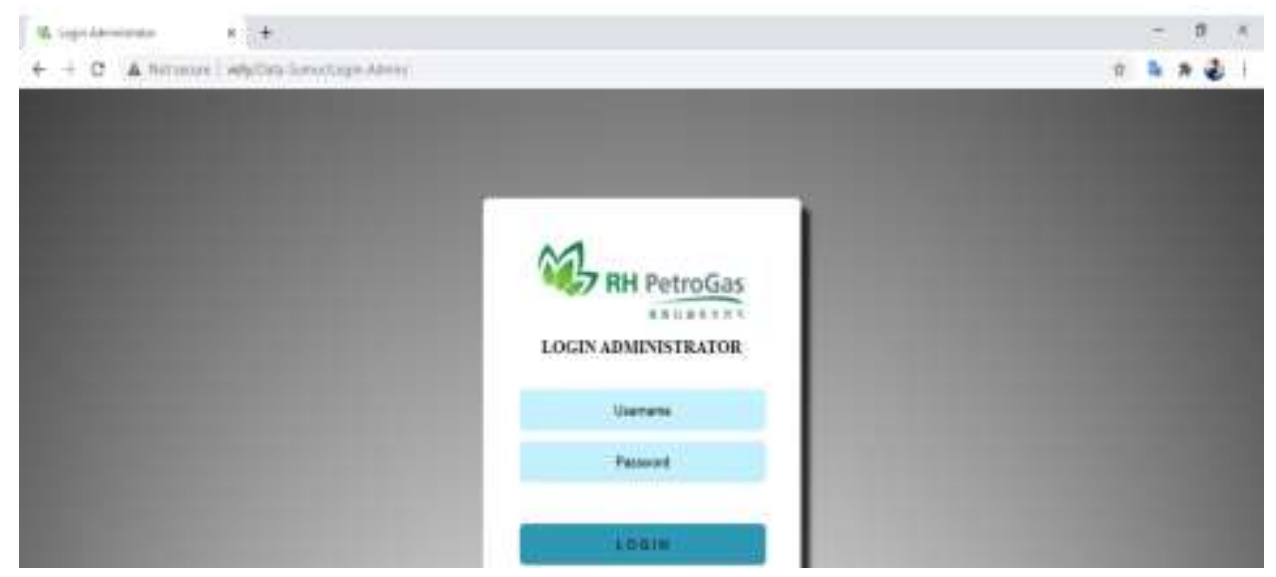

Gambar 4. Tampilan Halaman Admin

Gambar 4 Merupakan tampilan halaman depan (Login admin) dan admin terlebih dahulu dengan menginput username dan password agar bisa melihat laporan data operasional Sumur Sumur Minyak dan Gas. 


\section{Jurnal Electro Luceat [November] [2020]}

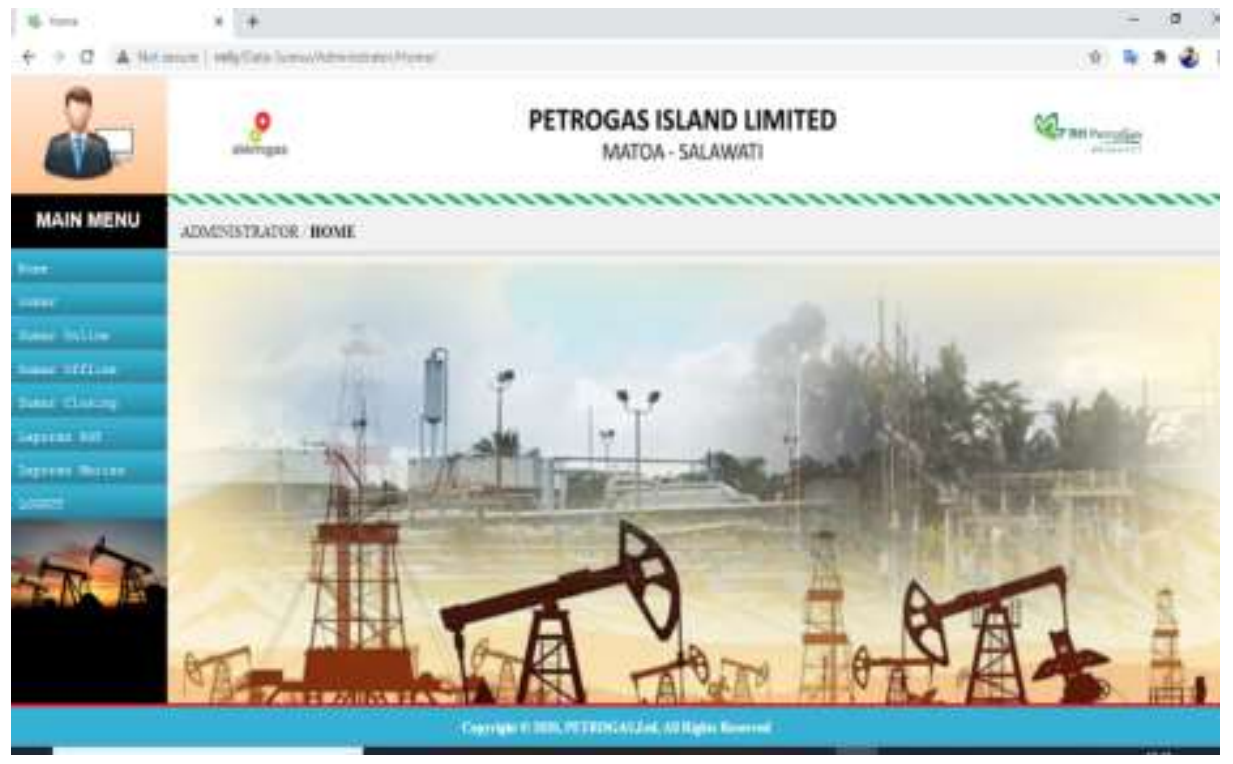

Gambar 5. Tampilan Halaman Admin

Gambar 5 merupakan halaman kerja admin. Admin dapat melakukan input, edit, dan hapus data.

c) Tampilan Login User

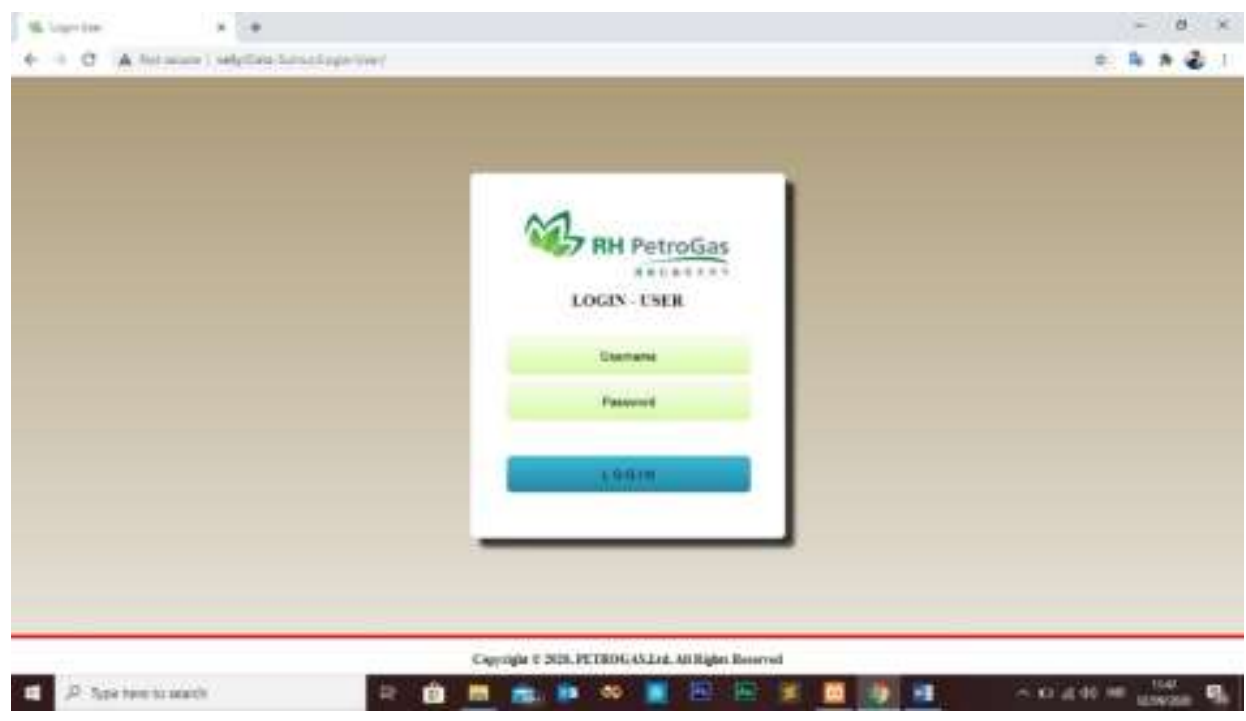

Gambar 6. Tampilan Login User/Pemimpn

Gambar 6 Merupakan tampilan halaman depan (Login user) dan user login terlebih dahulu dengan menginput username dan password agar bisa melihat laporan data operasional Sumur Sumur Minyak dan Gas. 


\section{Jurnal Electro Luceat [November] [2020]}

d) Tampilan Halaman Admin / Data Sumur

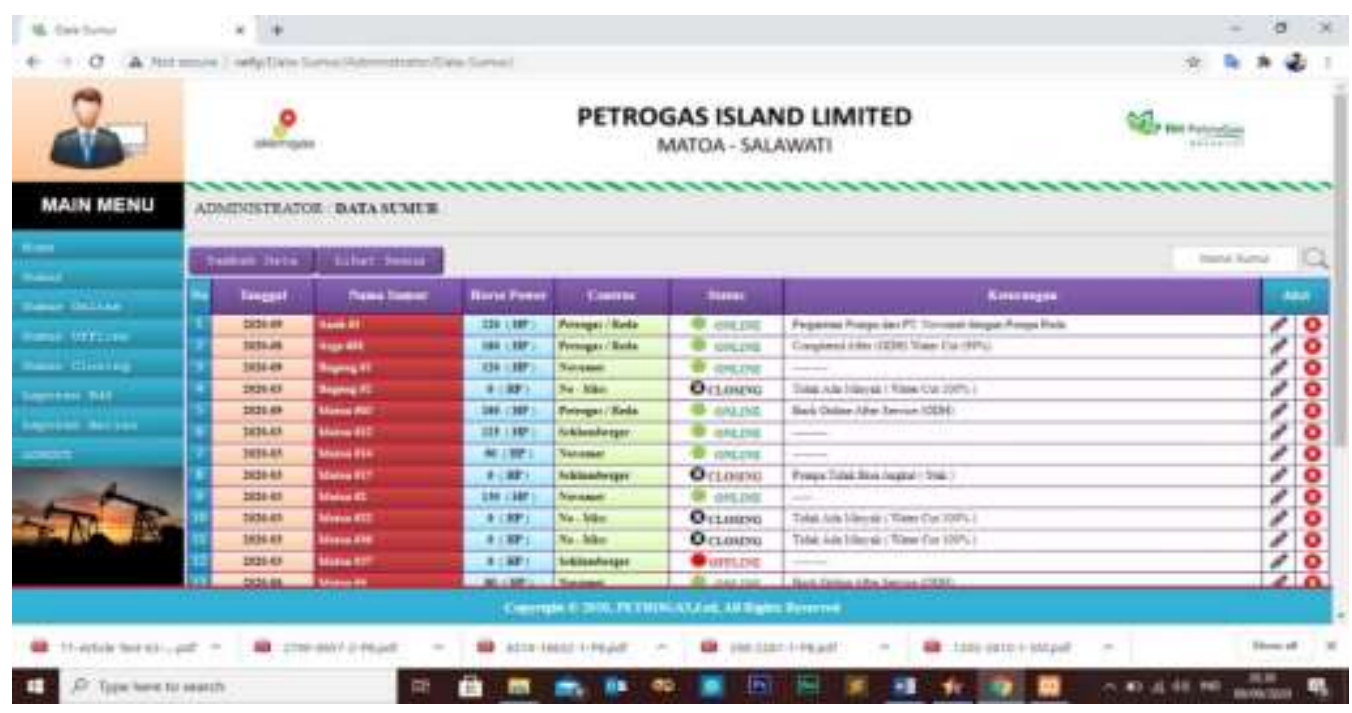

Gambar 7. Tampilan Halaman Data Sumur Online, Offline dan Closing

Gambar 7 Merupakan Tampilan Halaman Data Sumur - Sumur Minyak dan Gas. Dimana halaman ini adalah halaman Kerja admin dan Admin dapat melihat data sumur minyak dan Gas, dan juga dapat menambahkan data, edit dan hapus.

e) Halaman Download Data

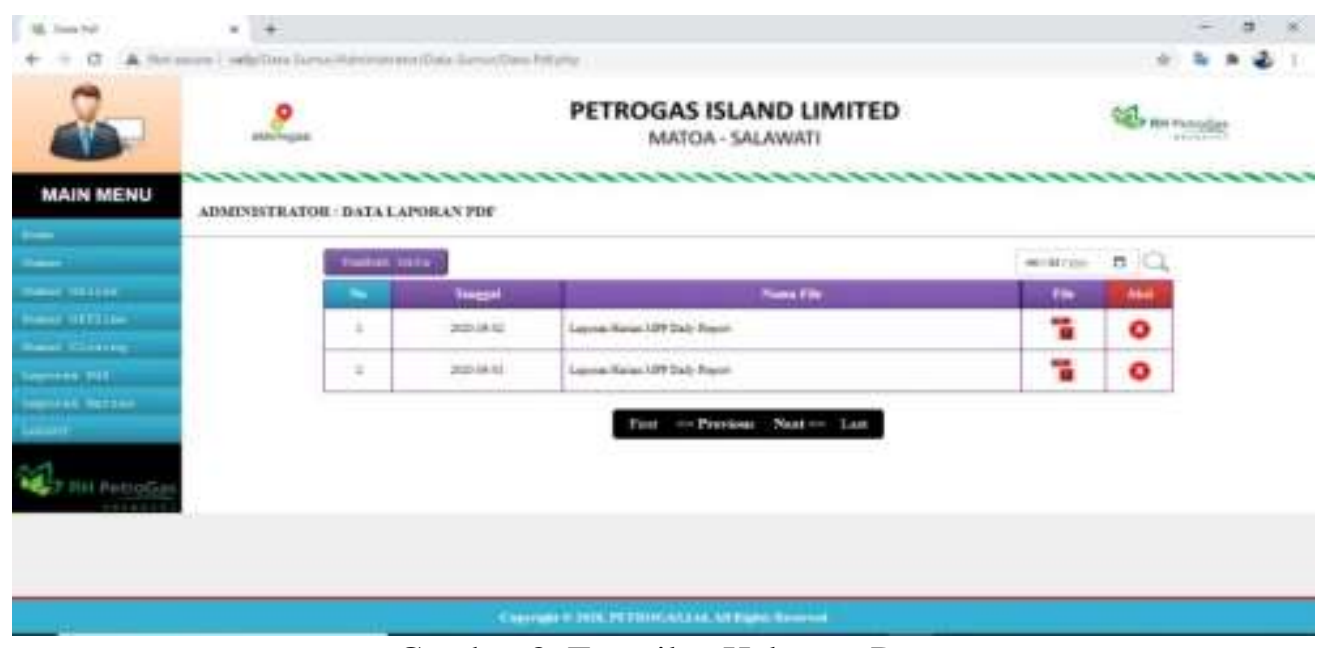

Gambar 8. Tampilan Halaman Data

Gambar 8 Merupakan tampilan halaman download dalam bentuk file pdf. Dalam halaman tersebut terdapat menu pencarian data, dimana user dapat mencari data yang di inginkan dan Mendowload data.

f) Halaman Laporan Harian 


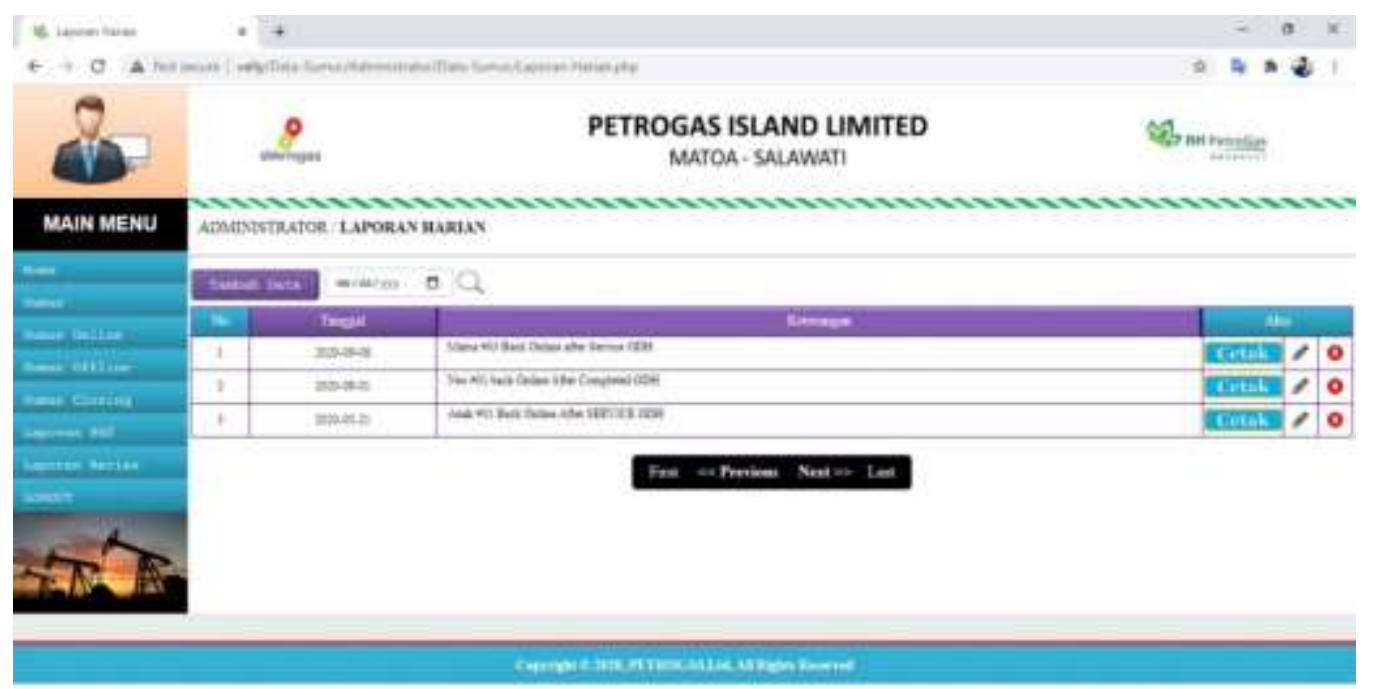

Gambar 9. Tampilan Halaman Laporan Harian Data Operasional Sumur Minyak dan Gas

Gambar 9 Merupakan Halaman Laporan Harian dimana Admin menginput data, tambahkan data, cetak, edit dan hapus data.

g) Halaman Laporan Harian

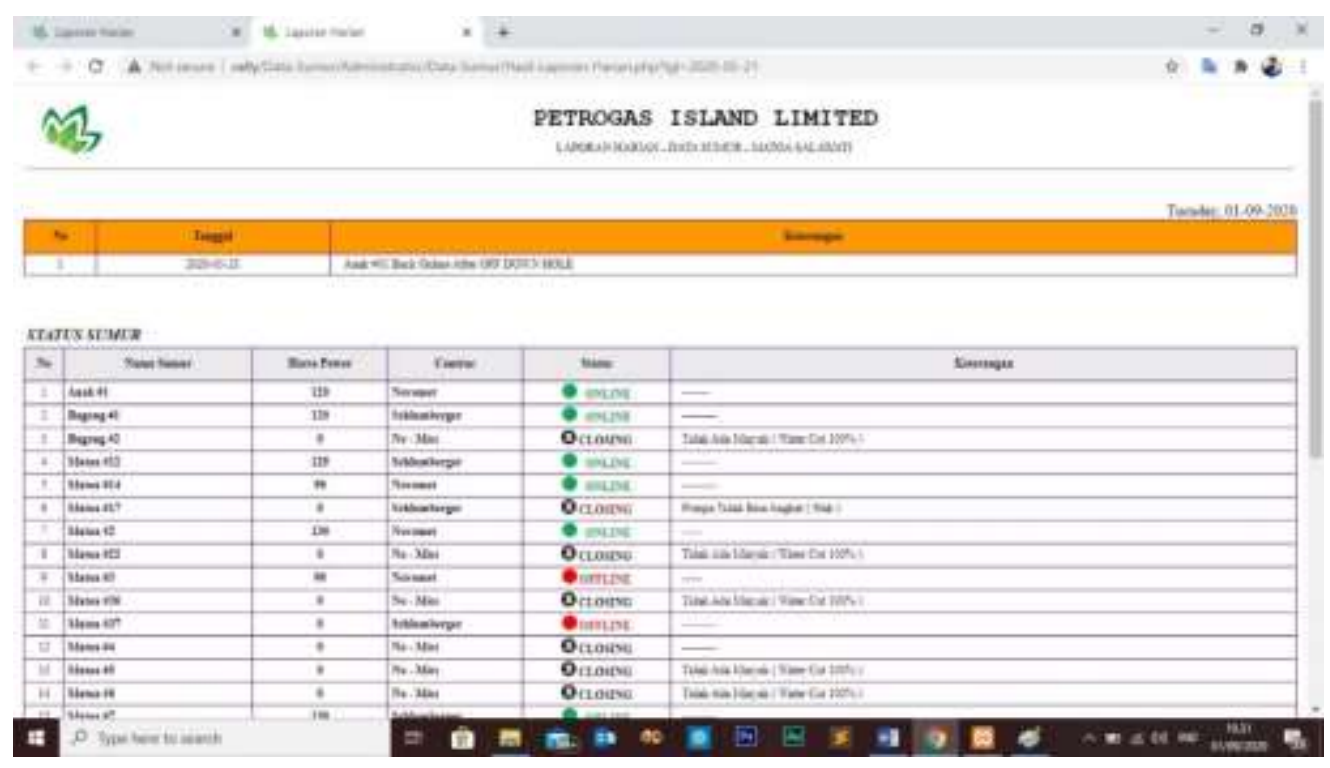

Gambar 10. Tampilan Halaman Laporan Harian Data Operasional Sumur Minyak dan Gas

Gambar 10 Merupakan Halaman laporan Harian yang akan di cetak atau di buatkan menjadi laporan dalam bentuk File PDF. 
h) Halaman input data

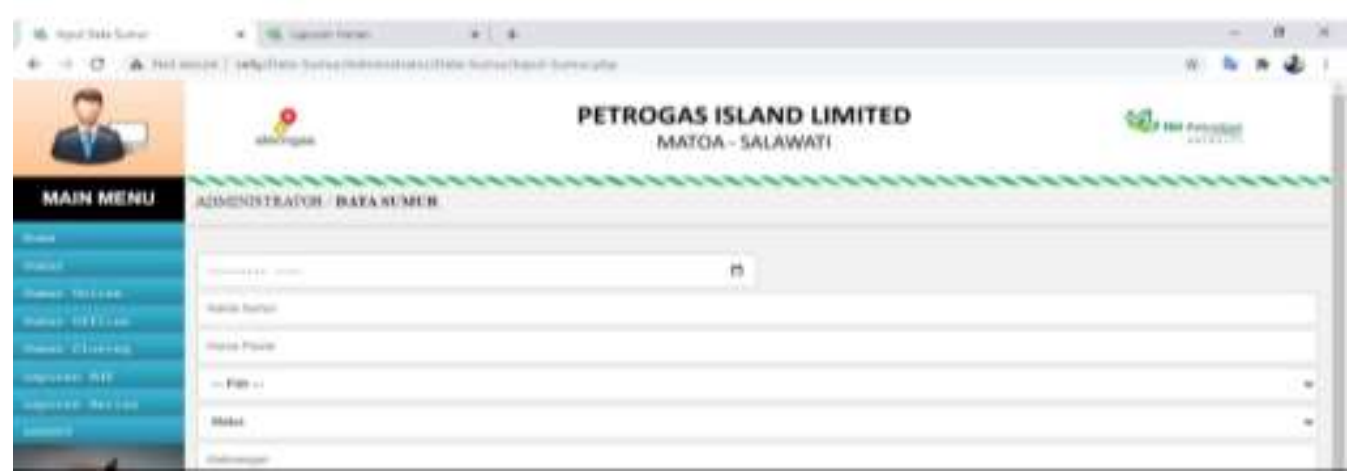

Gambar 11. Tampilan Halaman Input Data Operasional Sumur Minyak dan Gas

Gambar 4.9 Merupakan Halaman input data merupakan halaman input data untuk admin menginput data laporan operasional Sumur Minyak dan gas yang nantinya data tersebut tersimpan di data base dan data tersebut juga akan di convert dalam bentuk file pdf yang nantinya user dapat mendownload file tersebut.

\subsection{Analisa pengujian Sistem}

Pengujian sistem dilakukan untuk mengetahui kelemahan dari perangkat lunak yang sudah dibuat. Pengujian sistem ini juga bertujuan untuk melihat bagaimana sistem berjalan sesuai yang diharapkan atau memiliki kualitas yang baik.

Metode pengujian sistem ini menggunakan Black box testing yaitu suatu pengujian yang dilakukan hanya mengamati hasil eksekusi melalui data uji atau dapat mengevaluasi hanya dari tampilan luar (interface). Berikut adalah pengujian sistem perancangan aplikasi pelaporan data operasional sumur sumur minyak dan Gaas dan perbedaan sistem lama dengan sistem yang baru.

1) Pengujian sistem aplikasi pelaporan data operasional Sumur - Sumur Minyak dan Gas.

a. Pengujian sistem login Admin /user

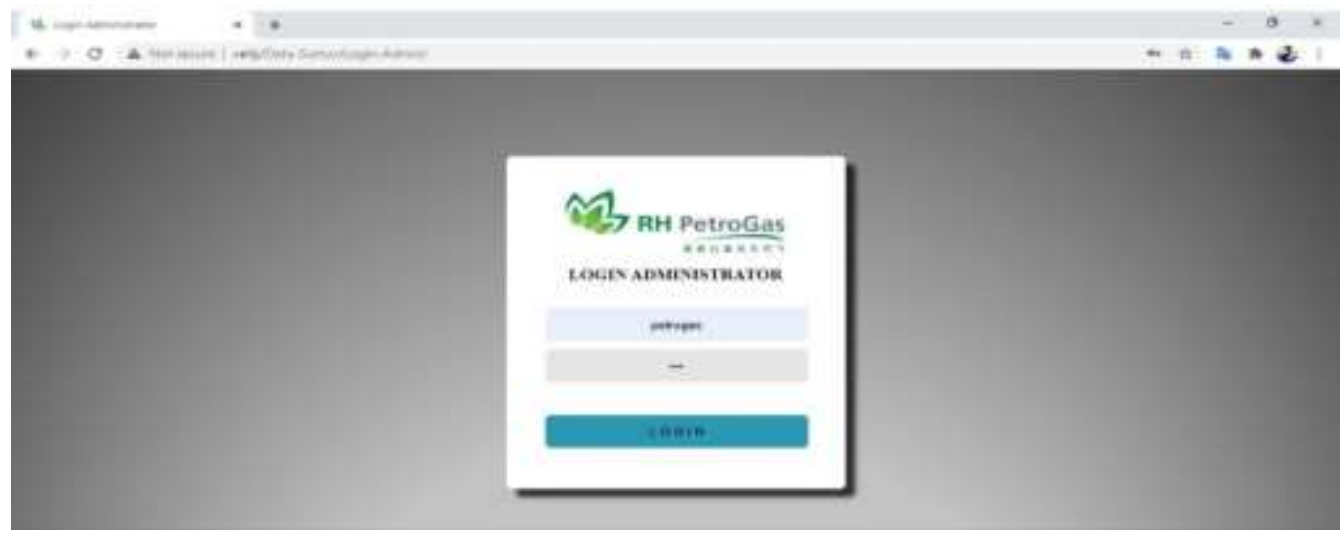

Gambar 12. Tampilan Halaman Login Admin / User. 
b. Pengujian sistem Tampilan Setelah Login Admin

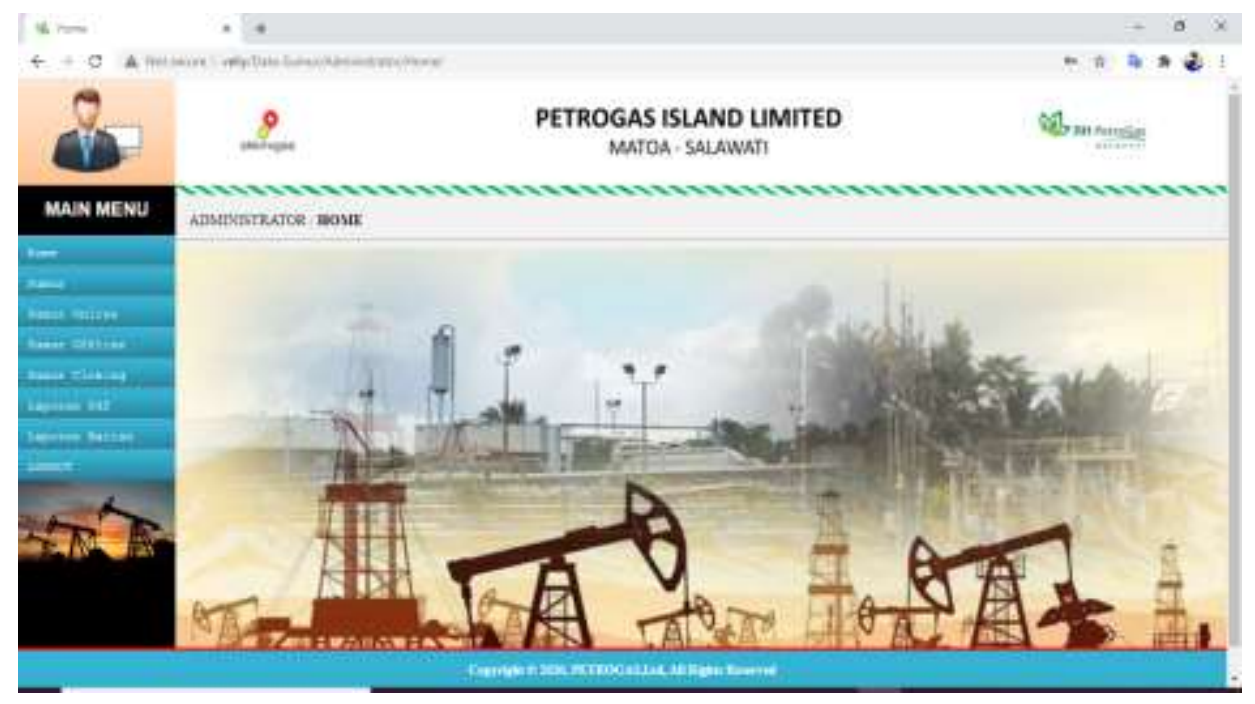

Gambar 13. Tampilan Setelah Login Admin / User Berhasil

c. Pengujian sistem input data

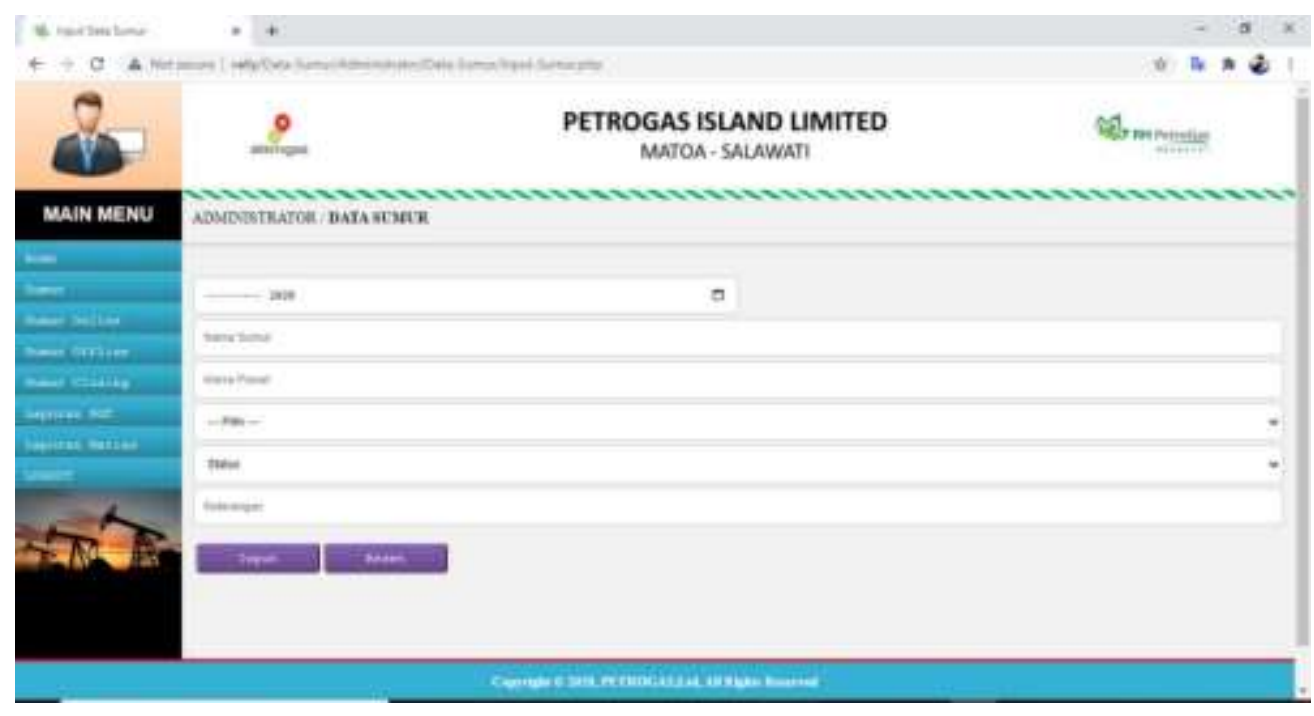

Gambar 14. Tampilan Menu Input Data

Dalam menu input data ini admin dapat menginput data mereka dan mengupload data tersebut maka data tersebut akan tersimpan ke dalam database. Setelah itu data laporan tersebut akan tampil di menu MPP Daily Report yang sudah tersedia seperti gambar dibawah ini. 
d. Pengujian sistem

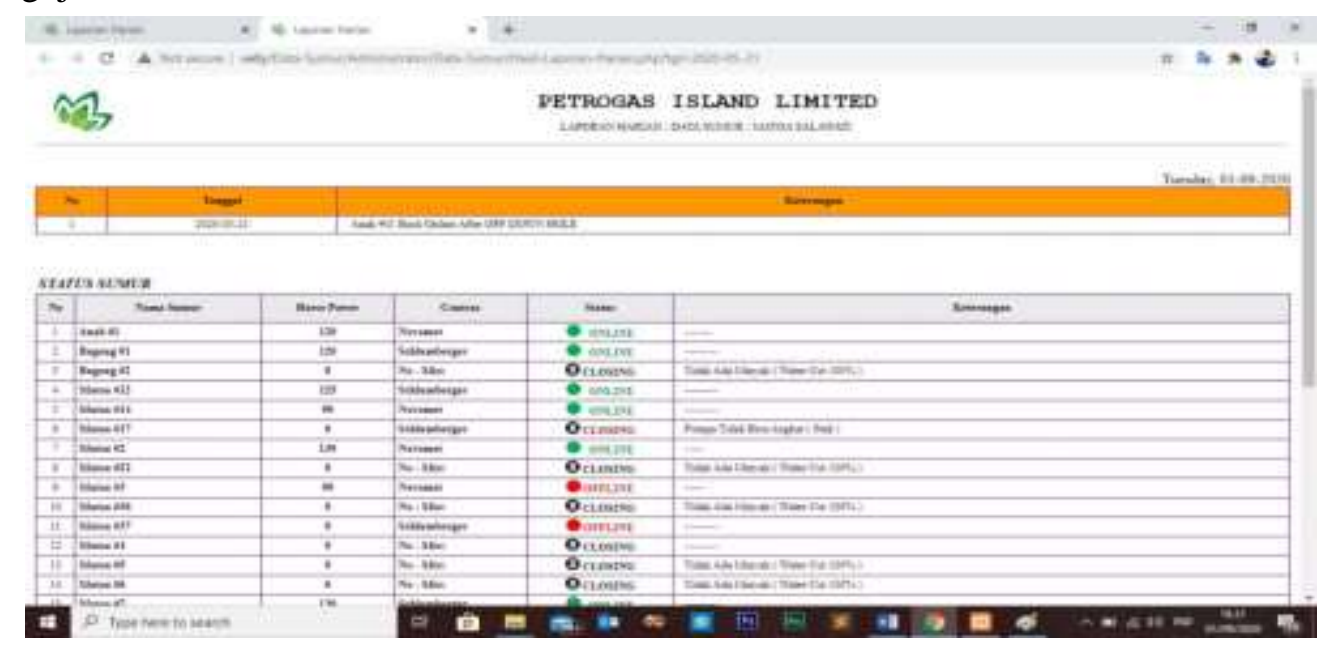

Gambar 15. Tampilan download Laporan Pendataan sumur minyak

\section{KESIMPULAN DAN SARAN}

\subsection{Kesimpulan :}

Kesimpulan dari Aplikasi Pelaporan Data Operasional Sumur - sumur Minyak dan Gas Di Petrogas Island Limited Salawati:

1. Sistem pelaporan data Sumur-Sumur Minyak dan Gas yang belum terkomputerisasi secara optimal di Petrogas Island Limited Salawati membuat proses pelaporan data kurang efektif dan efisien.

2. Sistem pelaporan data ini dibuat untuk membantu karyawan khususnya clerck dan division production maintenance untuk menyimpan data laporan tersebut apabila suatu saat data tersebut di perlukan, Serta juga untuk mengurangi pemakaian kertas yang berlebihan.

3. Dengan adanya sistem pelaporan data operasional Sumur Minyak dan Gas ini, diharapkan dapat melakukan pelaporan data secara efektif dan terhindar dari kesalahan.

\subsection{Saran}

Adapun saran yang diberikan dalam pelaporan data adalah sebagai berikut :

1. Memberikan perawatan pada sistem agar sistem dapat terjaga dari kerusakan.

2. Meningkatkan keamanan pada sistem agar pelaporan data lebih aman dan tidak disalahgunakan.

3. Melakukan backup data sesering mungkin agar tidak terjadi hal-hal yang tidak diinginkan seperti kehilangan data-data yang sudah ada.

\section{DAFTAR PUSTAKA}

[1] Amadatu, Yuvenjustus. (2010). Pengembangan Aplikasi Pelaporan Data Operasional Puskesmas Berbasis Web.

[2] Enjang, RK; Heryanto, Imam ; Raharjo, Budi. (2012). Modul Pemograman WEB (HTML, PHP, \& $M y S Q L)$, penerbit modula, bandung.

[3] Jefri Hutama Arb, Mangaras Yanu F, "Pengembangan Aplikasi Data Warehouse Untuk Pengelolaan Sumur Minyak“"

[4] Jogiyanto, H.M. (2004), (2010). Analisis Dan Desain Sistem Informasi, ( 2005). Pengenalan Komputer,penerbit Andi : Yogyakarta. 
JEC VOL. 6 NO. 2

Jurnal Electro Luceat [November] [2020]

[5] Lapu tombilayuk dan Zaini, (2020) "Prototipe Sistem Informasi Pengelolaan Data Statistik Terpadu Kota Bontang"

[6] Mawahib, Muhamad. (2011). Perancangan Sistem Pelaporan Nilai Ujian Sekolah Berstandar Nasional Pendidikan Agama Islam (USBN PAI) Berbasis Web (Studi kasus:Direktorat Pendidikan Agama Islam Pada Sekolah Direktorat jendral Pendidikan Islam Kementrian Agama RI).

[7] Peranginangin, Kasiman. (2006). Aplikasi WEB dengan PHP dan MySQL, penerbit Andi: Yogyakarta, 2006.

[8] Rizki Adhi Pratama, Jansen Wiratama, (2017)“ Pengembangan Sistem Informasi Pendukung Pelaporan Proses Lifting Minyak" (Studi Kasus: Pt. Emp Malacca Strait S.A. Tbk).

[9] Simarmata, Janner. (2006). Pengenalan Teknologi Komputer dan Informasi. penerbit Andi: Yogyakarta.

[10] Sudarma, S. (2010). Panduan Belajar MySQL Database server, penerbit mediakita : Jakarta. 